\title{
PENGARUH KONSENTRASI PAKLOBUTRAZOL PADA PERTUMBUHAN DAN PENAMPILAN TANAMAN SEDAP MALAM (Polyanthes tuberosa L.) DALAM POT
}

\author{
Effect of Paclobutrazol Concentration on Growth and Performance of \\ Tuberose (Polyanthes tuberose L.) in Pot \\ Rugayah $^{1 *}$, Kus Hendarto ${ }^{1}$, Yohannes C. Ginting ${ }^{1}$ dan Rina Ristiani ${ }^{1}$ \\ 1) Jurusan Agroteknologi, Fakultas Pertanian Universitas Lampung \\ Jln. Sumantri Brojonegoro No 1 Gedung Meneng Bandar Lampung 35145
}

Email: rugayah.1961@fp.unila.ac.id

\begin{abstract}
ABSTRAK
Tanaman sedap malam (Polyanthus tuberosa L.) merupakan tanaman hias populer di Indonesia sebagai bunga potong dan bunga tabur. Tanaman sedap malam dapat dijadikan sebagai bunga pot dengan membuat tangkai bunganya lebih pendek. Salah satu cara untuk mendapatkan tanaman sedap malam yang memiliki kriteria sebagai bunga pot adalah dengan pemberian zat penghambat tumbuh yaitu paklobutrazol. Penelitian ini dilakukan di Rumah Kaca Gedung Hortikultura Fakultas Pertanian Universitas Lampung pada November sampai Agustus 2017, bertujuan untuk mengetahui pengaruh konsentrasi paklobutrazol pada pertumbuhan dan penampilan tanaman sedap malam dalam pot dan mengetahui konsentrasi paklobutrazol terbaik pada penampilan tanaman sedap malam dalam pot. Penelitian ini menggunakan rancangan acak kelompok (RAK) dengan perlakuan tunggal 6 taraf konsentrasi paklobutrazol yaitu 0, 75, 150, 225, 300, dan 375 ppm dengan 3 kali ulangan. Homogenitas ragam diuji dengan uji Barttlet dan adivitas diuji dengan uji Tukey. Selanjutnya, diuji dengan uji F dan apabila signifikan dilanjutkan dengan uji Beda Nyata Terkecil (BNT) pada taraf 5\%. Hasil penelitian menunjukkan bahwa pemberian kosentrasi paklobutrazol pada pertumbuhan vegetatif hanya berpengaruh nyata pada lingkar batang semu dan semua variabel pada pertumbuhan generatif kecuali panjang floret. Konsentrasi paklobutrazol yan diberikan hingga 375 ppm belum didapatkan hasil yang optimum.
\end{abstract}

Kata kunci: Sedap malam, konsentrasi, paklobutrazol

\begin{abstract}
Tuberose (Polyanthus tuberosa L.) is a popular ornamental plant in Indonesia as cut flowers and sowing flowers. It can be used as potted flowers by making the flower stalks shorter. One way to get tuberose that have criteria as potted flowers is by administering growth inhibitors using Paclobutrazol. This research was conducted at the Greenhouse of the Horticultural Building, Faculty of Agriculture, University of Lampung in November to August 2017, aimed to determine the effect of the concentration of paclobutrazol on the growth and appearance of tuberose and to determine the best concentration of paclobutrazol in the appearance of potted tuberose. This study used a randomized block design (RCBD) with a single treatment with 6 levels of paclobutrazol concentration, namely 0, 75, 150, 225, 300, and 375 ppm with 3 replications. Homogeneity of variance was tested by Bartlett test and additivity was tested by Tukey test. Then, it was continued with the F test and with the Least Significant Difference test (LSD) at the 5\% level. The results showed that administration of paclobutrazol was significantly affected pseudo stem circumference and all variables of generative growth except the length of the florets. The concentration of paclobutrazol up to 375 ppm has not obtained optimum results.
\end{abstract}

Keywords: Concentration, growth, paclobutrazol, tuberose 


\section{PENDAHULUAN}

Pada era modern saat ini, bunga pot merupakan salah satu usaha bisnis yang banyak dikembangkan karena memiliki daya tarik. Daya tarik bunga pot yaitu dapat dijadikan sebagai penghias dalam maupun luar ruangan, penghias meja dalam bentuk vas bunga atau penghias taman halaman rumah, dan dapat dijadikan sebagai bingkisan hadiah. Selain itu juga, bunga pot tidak memerlukan tempat yang luas dan dengan adanya bentuk serta ukuran pot yang bervariasi membuat bunga pot banyak diminati oleh masyarakat terutama di daerah perkotaan. Sejalan dengan meningkatnya kesadaran masyarakat terhadap lingkungan yang indah dan asri, kebutuhan tanaman hias semakin meningkat setiap tahunnya termasuk tanaman sedap malam.

Tanaman sedap malam (Polyanthus tuberosa L.) termasuk famili Agavaceae yang berasal dari Meksiko. Tanaman ini telah beradaptasi di Indonesia tepatnya di Bangil Kabupaten Pasuruan sejak 95 tahun yang lalu. Tanaman sedap malam merupakan tanaman hias populer di Indonesia, karena memiliki bunga yang indah dan harum (Prahardini, 2006). Menurut Zuhrah et al. (2010) kebutuhan tanaman sedap malam (Polianthes tuberosa L.) semakin meningkat setiap tahunnya, baik sebagai bunga potong, bunga tebar, maupun minyak aksiri.

Sampai saat ini tanaman sedap malam diminati hanya dalam bentuk bunga potong dan bunga tabur. Namun, tanaman sedap malam dapat dijadikan sebagai bunga pot dengan membuat tangkai bunganya lebih pendek. Salah satu cara untuk mendapatkan tanaman sedap malam yang memiliki kriteria sebagai bunga pot adalah dengan pemberian zat penghambat tumbuh. Salah satu zat penghambat tumbuh yang dapat digunakan untuk memendekkan tanaman adalah paklobutrazol. Menurut Widaryanto (2011) paklobutrazol merupakan salah satu bentuk zat pengatur tumbuh yang bersifat menghambat biosintesis giberelin sehingga pertumbuhan vegetatif tanaman terhambat. Prinsip kerja paklobutrazol adalah menghambat reaksi oksidasi antara kauren dan asam kaurenoat pada sintesis giberelin, sehingga terjadi penekanan pada batang tanaman. Paklobutrazol dapat diaplikasikan dengan cara penyemprotan, penyiraman melalui media tanam, atau injeksi melalui batang.

Aplikasi paklobutrazol yang memberikan pengaruh terhadap penampilan bunga melati terbaik sebagai bunga pot adalah antara 200 sampai 400 ppm (Widyaningrum, 2005). Hasil penelitian Timur et al (2015), pemberian paklobutrazol dengan konsentrasi 200 ppm dapat memperpendek tinggi tanaman, mengurangi penambahan jumlah daun, dan mengurangi jumlah tunas pada tanaman gerbera lokal. Sampai saat ini penggunaan paklobutrazol untuk mengubah penampilan tanaman sedap malam sebagai bunga pot belum banyak dikaji. Oleh sebab itu, perlu diteliti efektivitas pemberian beberapa konsentrasi penggunaan paklobutrazol pada tanaman sedap malam.

Pengaruh pemberian paklobutrazol pada beberapa tanaman hias berbeda pada berbagai taraf konsentrasi. Konsentrasi dan waktu pemberian yang tepat dapat meningkatkan efektivitas penggunaan paklobutrazol. Oleh sebab itu untuk mengetahui hal tersebut, perlu dilakukannya penelitian mengenai pemberian paklobutrazol pada berbagai taraf konsentrasi yaitu $0,75,150,225,300$ dan 375 ppm terhadap tanaman sedap malam. Pemberian paklobutrazol pada berbagai konsentrasi tersebut diduga akan memberikan pengaruh yang berbeda terhadap penampilan tanaman sedap malam dalam pot.

\section{METODE PENELITIAN}

Penelitian ini dilaksanakan di rumah kaca Gedung Hortikultura Fakultas Pertanian Universitas Lampung pada November sampai Agustus 2017. 
Penelitian ini menggunakan rancangan percobaan berupa rancangan acak kelompok (RAK) dengan perlakuan tunggal 6 taraf konsentrasi paklobutrazol dengan 3 kali ulangan. Konsentrasi paklobutrazol yang diberikan: $0 \mathrm{ppm}\left(\mathrm{p}_{0}\right), 75 \mathrm{ppm}\left(\mathrm{p}_{1}\right), 150 \mathrm{ppm}$ $\left(\mathrm{p}_{2}\right), 225 \mathrm{ppm}\left(\mathrm{p}_{3}\right), 300 \mathrm{ppm}\left(\mathrm{p}_{4}\right)$, dan 375 ppm ( $\left.b_{5}\right)$. Satuan percobaan terdiri dari 3 pot, masing-masing pot terdiri dari 1 tanaman. Homogenitas ragam diuji dengan uji Barttlet, sedangkan adivitas diuji dengan uji Tukey.Jika asumsi terpenuhi, maka data dianalisis dengan sidik ragam, perbedaan nilai tengah perlakuan diuji dengan Uji Beda Nyata Terkecil (BNT) pada taraf $5 \%$.

Penelitian ini dilaksanakan melalui beberapa tahapan, yaitu: pembuatan larutan paklobutrazol dengan konsentrasi 0 ppm, 75 ppm, 150 ppm, 225 ppm, 300 ppm dan 375 ppm dengan membuat larutan stok terlebih dahulu. Larutan stok konsentrasi 375 ppm dibuat dengan cara melarutkan paklobutrazol sebanyak $375 \mathrm{ml}$ kemudian ditambah aquades dan ditera hingga volumenya menjadi 1 liter. Selanjutnya mengambil larutan stok dengan konsentrasi yang telah ditentukan dan melarutkannya dengan aquades hingga volume $500 \mathrm{ml}$.

Bibit tanaman sedap malam yang digunakan pada penelitian ini berasal dari lahan sedap malam di Hortipark Bandarlampung yang telah ditanam selama 3 tahun. Rumpun sedap malam dibongkar untuk dipisahkan berdasarkan ukuran umbi, yang nantinya dijadikan sebagai dasar pengelompokkan. Bahan tanam yang digunakan yang memiliki umbi anakan dengan ukuran diameter 1-3 cm. Kelompok I (besar: $\geq 2 \mathrm{~cm}$ ), kelompok II (sedang: 1,5$2 \mathrm{~cm}$ ), dan kelompok 3 (kecil: 1,5-1 cm) (Gambar 1) untuk ditanam dalam pot yang sudah diisi media tanam berupa campuran tanah, sekam, dan pupuk kandang dengan perbandingan volume 2:1:1.. Penanaman dilakukan pada pot berukuran $24 \mathrm{~cm}$ yang telah diisi media tanam. Sebelum dilakukan penanaman, akar dan umbi sedap malam direndam dalam fungisida yang berbahan aktif Mankozeb 80\% (2 g/l) selama 15 menit. Pemupukan dilakukan pada saat bibit tanaman berumur 1 MST dengan NPK Nitrophoska (15:15:15) sebanyak 3 g/pot dan pemberian diulang pada 9 minggu setelah tanam sebanyak $10 \mathrm{~g} /$ pot. Selain jenis pupuk NPK juga diberikan pupuk daun berupa Growmore (32:10:10) yang diaplikasikan pada umur 3 MST dengan cara disemprot ke daun dengan konsentrasi $2 \mathrm{~g} / \mathrm{l}$.

Pemberian NPK Nitrophoska dilakukan dua kali, sementara Growmore diaplikasikan sampai 10 MST dengan interval pemberian satu minggu sekali. Pada saat memasuki fase generatif dilakukan pemberian pupuk Gandasil B (6:20:30) dengan konsentrasi 2 g/l. Pupuk Gandasil B diberikan dengan cara disemprotkan pada tanaman dengan menggunakan hand sprayer setiap satu minggu sekali pengganti pupuk growmore.

Aplikasi paklobutrazol pada tanaman dilakukan pada umur 14 minggu setelah tanam (saat tanaman sudah tumbuh dengan kondisi baik), sebanyak dua kali, yaitu pada minggu ke 14 setelah tanam dan satu minggu setelah aplikasi pertama. Konsentrasi paklobutrazol yang diberikan sesuai dengan perlakuan masing-masing. Larutan pacloburazol diberikan pada tanaman dengan cara disiramkan pada media tanam sebanyak $50 \mathrm{ml} /$ pot, sehingga total larutan paklobutrazol yang diterima oleh tanaman adalah $100 \mathrm{ml} /$ pot. Variabel yang diamati pada penelitian ini meliputi tinggi tanaman, jumlah daun, lingkar batang semu, waktu muncul anakan, jumlah anakan, waktu muncul kuncup bunga, panjang tangkai bunga, diameter tangkai bunga, panjang floret, jumlah floret, waktu mekar bunga, dan masa mekar bunga.

\section{HASIL DAN PEMBAHASAN}

Hasil penelitian menunjukan bahwa pemberian paklobutrazol pada taraf konsentrasi 0, 75, 150, 225, 300 dan 375 ppm pada pertumbuhan vegetatif hanya berpengaruh nyata pada lingkar batang semu, tetapi berpengarug nyata pada semuan 
variabel pertumbuhan generatif, kecuali pada panjang floret (Tabel 1). Pemberian paklobutrazol dengan konsentrasi 375 ppm menghasilkan lingkar batang semu yang terbesar yaitu $6,84 \mathrm{~cm}$ (Gambar 2). Hasil penelitian ini juga menunjukkan bahwa perbedaan ukuran umbi tanaman sebagai dasar pengelompokan (Gambar 1) berpengaruh nyata pada semua variabel pengamatan, kecuali pada variabel pengamatan jumlah anakan dan panjang floret.

Tabel 1. Rekapitulasi analisis ragam pengaruh konsentrasi paklobutrazol pada penampilan tanaman sedap malam dalam pot

\begin{tabular}{lll}
\hline \multicolumn{1}{c}{ Variabel } & \multicolumn{2}{c}{ Pengaruh } \\
& Kelompok & Perlakuan \\
\hline Tinggi tanaman & $*$ & tn \\
Jumlah daun & $*$ & tn \\
Lingkar batang semu & $*$ & $*$ \\
Waktu muncul anakan & $*$ & tn \\
Jumlah anakan & tn & tn \\
Waktu muncul kuncup & $*$ & $*$ \\
bunga & & \\
Panjang tangkai bunga & $*$ & $*$ \\
Diameter tangkai & $*$ & $*$ \\
bunga & & \\
Panjang floret & tn & tn \\
Jumlah floret & $*$ & $*$ \\
Waktu mekar bunga & $*$ & $*$ \\
Masa mekar bunga & $*$ & $*$ \\
\hline
\end{tabular}

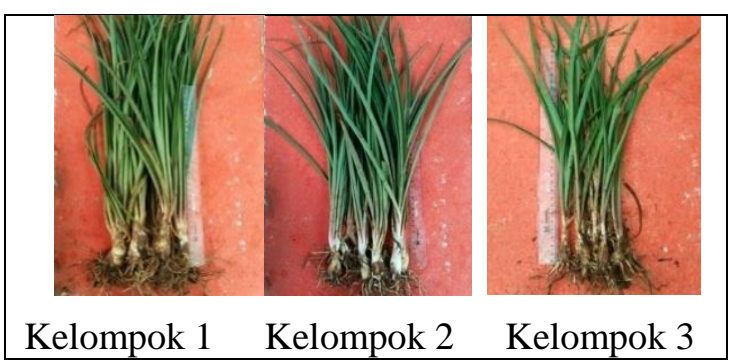

Gambar 1. Pengelompokan berdasar bibit

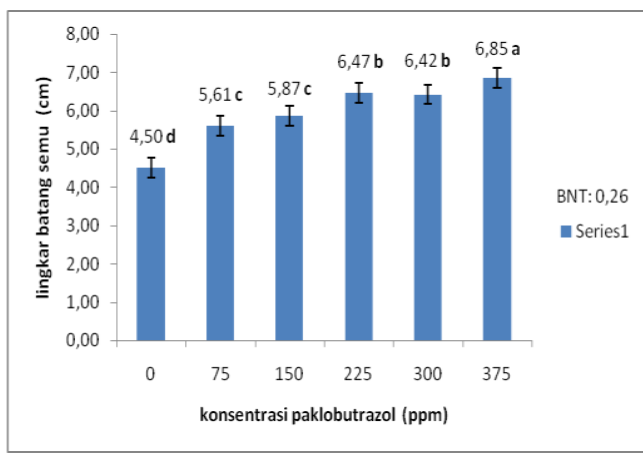

Gambar 2. Pengaruh konsentrasi paklobutrazol pada lingkar batang semu 13 minggu setelah aplikasi

Pemberian paklobutrazol konsentrasi 0-375 ppm tidak berpengaruh nyata pada tinggi tanaman dan jumlah daun tanaman sedap malam, tetapi berpengaruh nyata pada lingkar batang semu. Bagian batang sedap malam tidak muncul di permukaan karena sedap malam tidak memikili batang sejati, tetapi yang muncul di permukaan adalah batang semu. Oleh karena itu pengukuran tinggi tanaman sedap malam dilihat dari panjangnya daun sehingga efek pemberian paklobutrazol tidak terlihat pada pemendekan batang tetapi meningkatkan diameter pangkal batang semu (Gambar 2). Hal ini sesuai dengan pendapat Khrisnamoorthy (1981) yang menyatakan bahwa paklobutrazol mempunyai pengaruh fisiologis menghambat pertumbuhan batang dengan menghambat pembelahan sel pada meristem sub apikal, sedangkan pembentukan daun tidak dipengaruhinya. Hal ini didukung oleh penelitian Widaryanto et al. (2011), yang menunjukkan bahwa waktu pemberian dan konsentrasi paklobutrazol tidak berpengaruh nyata terhadap jumlah daun tanaman bunga matahari. Jumlah daun berhubungan dengan jumlah buku pada batang tanaman. Paklobutrazol menekan pemanjangan ruas batang, tetapi tidak mempengaruhi jumlah buku pada batang. Hasil penelitian Wahyurini (2002), menunjukkan bahwa pemberian paklobutrazol tidak berpengaruh nyata pada tinggi tanaman, jumlah daun, 
waktu muncul anakan, dan jumlah anakan beberapa kultivar tanaman Lily (Lilium longiflorum). Pemberian paklobutrazol dengan konsentrasi tertinggi (400 mg/l) menghasilkan jumlah daun terbanyak.

Terjadinya peningkatan batang semu akibat pemberian paklobutrazol menurut pendapat Cathey (1964) adalah zat penghambat tumbuh dapat menghambat biosintesis giberelin dan mempertebal batang. Penebalan batang disebabkan karena produksi sel di dalam kambium distimulir dan terjadi peningkatan volume dari sel parenkim di daerah korteks. Hal ini didukung oleh hasil penelitian Widaryanto dkk (2011), yang menunjukkan bahwa pemberian paklobutrazol dapat mempertebal diameter batang tanaman bunga matahari.

Pemberian paklobutrazol dengan konsentrasi 0-375 ppm tidak berpengaruh pada waktu muncul anakan dan jumlah anakan. Hal ini didukung oleh penelitian Ardigusa dan Sukma (2015), pemberian pakobutrazol dengan konsentrasi 0, 62,5, 125, dan $250 \mathrm{ppm}$ tidak berpengaruh nyata pada jumlah anakan tanaman Sanseivera, namun semakin besar tingkat konsentrasi paklobutrazol yang diberikan, waktu muncul anakan lebih cepat dan jumlah anakan yang lebih banyak.

Pemberian paklobutrazol sampai konsentrasi 375 ppm menyebabkan waktu muncul kuncup bunga lebih lama. Waktu muncul kuncup bunga yang lama menyebabkan waktu mekar bungapun lebih lama. Hal ini sesuai dengan percobaan Techato et al. (2009), mengenai peran paklobutrazol dalam pembungaan tanaman anggrek Dendrobium; aplikasi paklobutrazol dengan konsentrasi tertinggi 1 ppm belum dapat mempercepat pembungaan dan meningkatkan jumlah kuncup bunga. Hal ini didukung oleh penelitian Astika (2014), pemberian paklobutrazol dengan konsentrasi tertinggi 60 ppm menyebabkan tanaman gerbera tidak menghasilkan kuncup bunga sedangkan pada konsentrasi 20 ppm dapat menghasilkan kuncup bunga tercepat.
Rochimah (1996), menunjukkan bahwa penggunaan cycocel, paklobutrazol, dan daminozide pada tanaman Kalanchoe belum mampu mempercepat inisiasi kuncup bunga. Selain itu, menurut penelitian Sirait (2002), pemberian paklobutrazol 75, 150, dan $300 \mathrm{ppm}$ serta daminozide pada tanaman gardenia tidak berpengaruh terhadap saat terbentuknya kuncup bunga.

Latimer (2001), menyatakan perbedaan respons jenis tanaman terhadap aplikasi paklobutrazol menjadi suatu kendala dalam pembungaan tanaman, paklobutrazol juga menyebabkan penghambatan biosintesis giberelin endogen aktif yang merupakan promotor pembungaan. Weaver (1972), mengemukakan bahwa paklobutrazol dapat menghambat pertumbuhan tanaman dan mempengaruhi pada proses pembungaan. Saat pertumbuhan terhambat terdapat kompetisi penyerapan nutrisi tanaman untuk pembungaan sehingga menyebabkan proses penundaan dalam pembentukan bunga.

Pemberian paklobutrazol dengan konsentrasi 375 ppm menghasilkan diameter tangkai bunga terbesar jika dibandingkan dengan perlakuan kontrol. Hal ini sesuai dengan yang dikemukakan oleh Weaver (1972), bahwa, paklobutrazol dapat menghambat pertumbuhan vegetatif tanaman sehingga pertumbuhan tinggi batang dan tangkai bunga menjadi terhambat dan cenderung lebih tebal. Hasil penelitian Widyastuti (2002) menunjukkan bahwa, paklobutrazol selain dapat meningkatkan warna hijau daun, juga dapat mempertebal batang tanaman dan menghambat etiolasi. Meningkatnya diameter tangkai bunga karena adanya peningkatan lingkar batang semu. Pada pemberian paklobutrazol 375 ppm menghasilkan lingkar batang semu yang terbesar.

Pemberian paklobutrazol tidak berpengaruh nyata terhadap panjang floret tetapi berpengaruh nyata pada peningkatan jumlah florat. Hal ini sesuai dengan yang dikemukakan oleh Khrisnamoorthy (1981), yang menyatakan bahwa paklobutrazol 
mempunyai pengaruh fisiologis menghambat pertumbuhan batang dengan menghambat pembelahan sel pada meristem sub apikal, sedangkan pembentukan daun, bunga, dan buah tidak dipengaruhinya. Pemberian paklobutrazol 150 dan 375 ppm mampu menghasilkan jumlah floret yang lebih banyak dibandingkan dengan perlakuan yang lain.

Hasil penelitian Rubiyanti (2014), pemberian konsentrasi paklobutrazol dan waktu aplikasi berpengaruh nyata terhadap jumlah bunga per tanaman pada mawar batik. Menurut Siti (2007), penggunaan paklobutrazol akan memberikan respons yang berbeda terhadap tanaman yang berbeda pula. Hal ini didukung oleh penelitian Karaguzel (2004), yang menyatakan bahwa konsentrasi pemberian paklobutrazol (2500 mg/tanaman) yang tinggi pada tanaman Lupinus varius menghasilkan jumlah bunga yang lebih sedikit dibandingkan kontrol begitu halnya pada tanaman Gladiolus tristis dengan semakin meningkatnya konsentrasi paklobutrazol yang diberikan maka jumlah bunga pada tanaman ini semakin sedikit.

Pemberian konsentrasi paklobutrazol berpengaruh nyata terhadap masa mekar bunga tanaman sedap malam dalam pot. Tanaman sedap malam yang diberi paklobutrazol 375 ppm menghasilkan masa mekar bunga yang lebih lama yaitu 7,22 hari, sedangkan tanaman yang tanpa diberi paklobutrazol masa mekar bunganya hanya 1,87 hari (Gambar 3). Hal ini dikarenakan tanaman yang diberi paklobutrazol memiliki batang semu yang lebih tebal dan diameter tangkai bunga yang lebih besar sehingga mampu menyimpan cadangan makanan maupun unsur hara dan air lebih banyak agar organ tanaman, dalam hal ini bunga, dapat bertahan lebih lama.

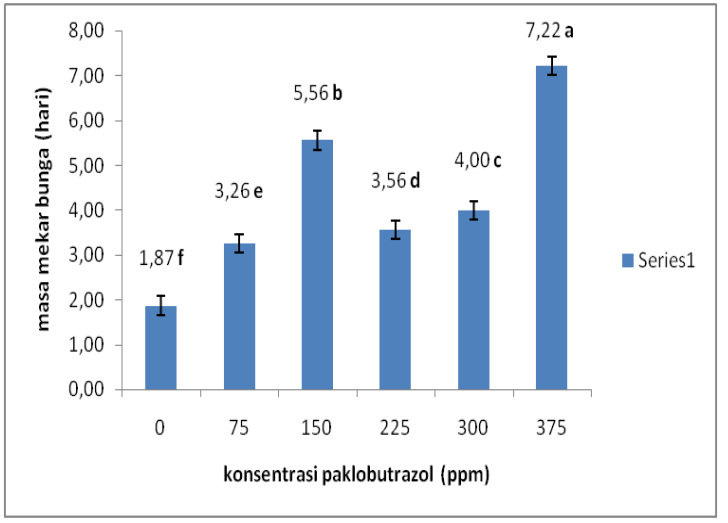

Gambar 3. Pengaruh konsentrasi paklobutrazol terhadap masa mekar bunga pada 22 minggu setelah aplikasi

Hal ini didukung oleh pernyataan Widyastuti (2002) bahwa, retardan dapat memperlambat kelayuan bunga dan tanaman yang diberi retardan akan lebih tahan terhadap stress air, suhu panas, suhu dingin dan asap selama diletakkan dalam berbagai kondisi ruangan. Hasil penelitian Widaryanto (2011), menunjukkan bahwa pemberian paklobutrazol pada semua konsentrasi dan waktu pemberian terhadap bunga bagian atas maupun bawah pada tanaman bunga matahari lebih tahan lama jika dibandingkan dengan kontrol. Tampilan tanaman pada pemberian berbagai konsentrasi paklobutrazol dapat dilihat pada Gambar 4. 


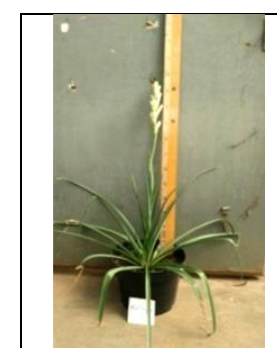

$0 \mathrm{ppm}$

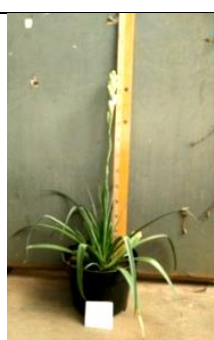

$75 \mathrm{ppm}$

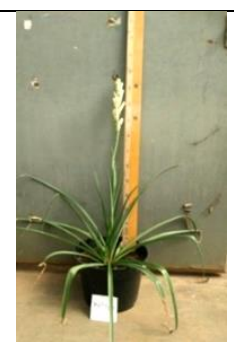

$150 \mathrm{ppm}$

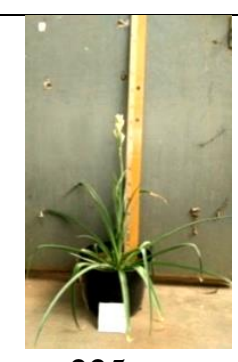

$225 \mathrm{ppm}$

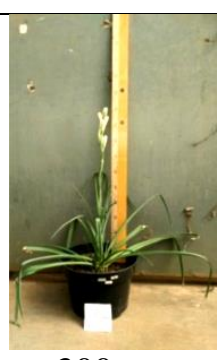

$300 \mathrm{ppm}$

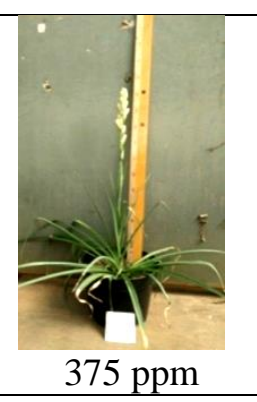

$375 \mathrm{ppm}$

Gambar 4. Penampilan visual tanaman sedap malam yang diberi perlakuan berbagai konsentrasi paklobutrazol

\section{KESIMPULAN}

Pemberian paklobutrazol dengan 6 taraf konsentrasi: $0,75,150,225,300$, dan 375 ppm tidak berpengaruh nyata terhadap semua variabel pengamatan vegetatif kecuali lingkar batang semu dan berpengaruh nyata terhadap semua variabel generatif kecuali panjang floret. Pemberian paklobutrazol dengan konsentrasi yang semakin meningkat cenderung meningkatkan lingkar batang semu, jumlah floret, diameter tangkai bunga, dan masa mekar bunga (ketahanan bunga). Pengelompokkan berdasarkan ukuran umbi memberikan pengaruh nyata pada semua variabel pengamatan kecuali pada variabel jumlah anakan dan panjang floret.

\section{UCAPAN TERIMAKASIH}

Ucapan terimakasih ditujukan kepada Fakultas Pertanian yang telah memberi dana penelitian melalui DIPA Fakultas tahun anggaran 2017.

\section{DAFTAR PUSTAKA}

Ardigusan dan Sukma. 2015. Pengaruh paclobutrazol terhadap pertumbuhan dan perkembangan tanaman Sanseviera (Sanseivera trifasciata Laurentii). Jurnal Hortikultura Indonesia, 6(1) : 45-53.

Astika, A.D. 2014. "Pemanfaatan Paclobutrazol dalam Budidaya Gerbera (Gerbera jamesonii) sebagai Tanaman Hias Pot". Skripsi. IPB. Bogor. 23 p.
Cathey, H. M. 1975. Comparative plant growth retarding activities at ancymidol with ACPC, Phosphon, Chlormequat and SADH on ornamental plant species. $J$. HortScience, 10: 216-240

Karaguzel, O., I. Baktir., S. Cakmakci. dan V. Ortacesme. 2004. Growth and flowering responses of Lupinus varius L. to paclobutrazol. HortScience, 39(7): 16591663.

Khrisnamoorthy, H.N. 1981. Plant growth substances including applications in agriculture. McGraw-Hill Publ. New Delhi. 214p.

Latimer, J.G. 1991. Growth retardants affect landscape of Zinnia, Impatiens and Marigold. Hortscience, 26(5): 557-560.

Prahardini, P. E. R. Teknologi Produksi Bunga Sedap Malam. Info Teknologi Pertanian. (52): 8.

Rochimah. 1996. "Pengaruh Konsentrasi Cycocel, Paclobutrazol dan B-9 terhadap Pertumbuhan dan Perkembangan Tanaman Kalanchoe (Kalanchoe blossfeldiana POLLN)". Skripsi. IPB. Bogor. $44 \mathrm{p}$.

Rubiyanti, N. 2014. Pengaruh konsentrasi paklobutrazol dan waktu aplikasi terhadap mawar batik (Rosa hybrida L.). Jurnal AgriSci., 1(4): 48-53.

Sirait, R.I.M. 2002. "Pengaruh Zat Penghambat Tumbuh Paclobutrazol dan Daminozide terhadap Pertumbuhan dan Perkembangan Gardenia Jasminoides Ellis". Skripsi. IPB. Bogor. 34 p.

Siti, F. S. 2007. Pengaruh retardan paclobutrazol terhadap pertumbuhan temulawak 
(Curcuma xanthorrhiza) selama Konsentrasi In Vitro. Jurnal Littri, 13(3): 93-97.

Techato S, Nujeen P, Muangsorn S. 2009. Paclobutrazol enhance budbreak and flowering of Friederick's Dendrobium orchid. J. Agri Tech., 5(1): 157-165.

Timur, A. Rugayah. S. Widagdo. 2015. Pengaruh konsentrasi paklobutrazol terhadap penampilan tanaman gerbera lokal (Gerbera jamesonii) dalam pot. Prosiding Seminar Nasional Sains \& Teknologi VI. Pp. 271-281.

Wahyurini, E. 2002. Stimulasi Pertumbuhan dan Perkembangan Beberapa Kultivar Lily dengan Aplikasi GA3 dan Paklobutrazol. Tesis. PPS IPB. 70 p.

Wattimena, G.A. 1988. Zat Pengatur Tumbuh Tanaman. Lembaga Sumber Daya Informasi IPB. Bogor. 17 p.
Weaver, R. J. 1972. Plant Growth Substances in Agriculture. San Fransisco, USA. Freeman. Pp 176-250.

Widaryanto, E., M. Baskara., A. Suryanto. 2011. Aplikasi paklobutrazol pada tanaman bunga matahari (Helianthus annuus L. cv. Teddy Bear) sebagai upaya menciptakan tanaman hias pot. Perhorti Lembang. 6 p.

Widianingrum, I. 2005. "Pengaruh Konsentrasi dan Frekuensi Pemberian Paklobutrazol Melalui Tanah pada Penampilan Tanaman Melati (Jasminum sambac L.) dalam Pot". Skripsi. Universitas Lampung. Bandar Lampung. 90 p.

Widyastuti, N. 2002. Pemendekan tanaman krisan pot dengan zat penghambat tumbuh.

http://www.iptek.net.id/ind/terapan_idx.

Zuhrah, A., N. Aini. T. Wardyati. 2010. Respons morphologi tanaman sedap malam (Polianthes tuberose L. cv. Roro Anteng) terhadap pemberian colchicine. Buana Sains, 10(2): 153-158. 